\title{
Relational Processes of Critical Thinking
}

\author{
Katrina Skewes McFerran ${ }^{1}{ }^{*}$, Susan Hadley ${ }^{2}$, Brynjulf Stige ${ }^{3}$ \\ 1 University of Melbourne, Australia \\ 2 Slippery Rock University, USA \\ 3 University of Bergen, Norway \\ *k.mcferran@unimelb.edu.au
}

Published: 1 March 2020

Welcome to the March 2020 edition of Voices: A World Forum for Music Therapy. Once again, we are proud of the collection of research and practice articles being launched in this edition. They represent a diversity of practices around the globe, as well as foci on research, reports, interviews, and more.

Authors from three of the articles reflect specifically on cultural diversity, which is deeply relevant to the Voices vision, that explicitly states: "The journal values inclusiveness and socio-cultural awareness and has increasingly nurtured a critical edge that refines the focus on cultural issues and social justice." One of these articles is an interview with two developers of music therapy in India, and is well located by the interviewer from their own position as an outsider with a deep respect for, and interest in, the practices there. This kind of transparent revealing of the pre-assumptions we bring to what we write is a common technique in critical thinking and writing, and one with which our forum is comfortable and familiar. This is also demonstrated in other articles that adopt a critical lens, such as the two systematic reviews of the literature focused in schools (Hip Hop for Wellbeing and Music Therapist/Teacher consultations), both by groups of Australian authors.

In different ways, authors throughout the edition have revealed themselves to our readership. This is named prominently in the article by Zoe Kalenderidis, a music therapist with lived experience as disabled who has taken the opportunity to explore this topic through an arts-based approach. This dismantling of the assumption that the therapist is 'well' and the client is 'not well' is another indicator of critical thinking within our field. Overt recognition of our shared humanity is a powerful way to shift thinking away from positions that disempower some to the benefit of others, and towards equity.

Voices is a forum for making suggestions for the development of practice, through reflections on our own positioning with regards to those we work with, and through considerations of the practical details of how we work. Niall McGuigan also reveals his own experience of learning how to be present as a student music therapist and explores the value of embodied as well as cognitive learning in music therapy training. Another pair of Irish authors also explore music therapy education, this time examining whether students are sufficiently prepared for verbal encounters, as well as musical dialogues. Based on interviews with three practitioners, they advocate for more training in this area. 
The final research article takes an objectivist design to explore a hypothesis about the effects of therapist positioning within Person Preferred Live Music on positive and negative affect, pain, and trust in the therapist with adults on a cardiovascular unit. Rather than referring to positioning in a critical sense, as noted above, these authors are focusing on the literal meaning of positioning - whether the music therapist is sitting or standing when providing patients with preferred songs. Results were inconclusive, but the therapists believed that sitting on a more even level with patients was more engaging.

The contrast between these two understandings of 'positioning' is, once again, representative of the Voices mission statement, which is a commitment to developing an egalitarian and interdisciplinary forum so that multiple voices can be heard, not just those that privilege critical perspectives and collaborative practices. One way that we have endeavoured to live these values as an editorial team has been through the introduction of transparent reviewing processes, a topic we discussed in detail in the editorial of the November issue in 2016. Please find more detail there about exactly what our transparent reviewing process involves.

By revealing the positions of editors and reviewers in relation to authors, it becomes possible to see the interpersonal relationships that are always at play in refereed academic publishing. Music therapy is a relatively small profession, so our decision to align with transparent reviewing processes - as described by The Committee on Publication Ethics (COPE) - has demonstrated that there are often connections between those being reviewed and those doing the reviewing, as well as the editing. We have become more conscious of these connections even as editors, and it has required us to review our recruitment processes so that we don't invite reviewers who have track records with authors to review their work. This has been complex enough, since sometimes we are not familiar with these shared track records. However, not all relationships are so formal, and it has become clear to us that informal relationships are also apparent to readers who are familiar with those involved. We are grateful to those readers who have written to us about this and questioned whether our reviewing processes are objective enough.

This is a wonderful question, and a fair one. How much value should we place on objectivity in reviewing, and how actual is the phenomenon of objective reviewing, even when it appears to be there, or when it is not revealed? The current edition demonstrates that many of our editors are also authors. That is one layer of interconnectedness. We also see that many of the people who accept our invitations to review are known to us, and it is our experience that when we invite people we don't know, they are more likely to say no. Also, it is important to us to choose reviewers who have a depth of knowledge and understanding of both the topic that is being explored as well as a commitment to social change. We recognise that everyone we invite is busy, so this is not taken personally, and it is worth noting that we are extremely grateful to those reviewers who dedicate hours to reviewing. But this level of transparency does lead us to contemplate whether our inter-relationships are too close, whether our networks are too limited, whether the field is big enough to tolerate the recognition that a relatively small group of people engage in editorial reviewing and editing. If you have constructive ideas to share about this, please email us to contribute to a dialogue about this process. And if you would like to be reviewer for Voices, please let us know, so that we can add you to our list of reviewers - also transparently placed on our webpage.

We will continue to deliberate these questions, particularly whether the perception of objectivity in reviewing is more valuable than the revelation of those inter-relationships that do exist. Our shared perspective on the editorial team is that bias always exists, and it is only when we acknowledge it that changes can be made. Perhaps we can and should go further. Another option in the COPE list was to publish the reviews themselves, so that readers could determine how rigorous the process has been in leading to publication. Clearly, there are several options to discuss and consider. 
In the meantime, we invite you to read our manuscripts, celebrate our authors and translators, applaud the time spent and the dedication of our editors and reviewers, and help us to continue to grow in our critical awareness. 